\title{
PREPARATION OF HYDROPHILIC BENTONITE GRAFTED MIXED MATRIX POLYVINYLCHLORIDE MEMBRANE WITH SUPERIOR HYDROPHILICITY
}

\author{
Pawan Kumar, Shobhit Dixit and Vijay Laxmi Yadav* \\ Department of Chemical Engineering \& Technology, IIT-BHU, \\ Varanasi-221005, Uttar Pradesh, India \\ *E-mail: vlyadaviitbhu2014@gmail.com
}

\begin{abstract}
This research study, by using a non-solvent induced phase separation method, an approach to prepare polyvinyl chloride membranes grafted with hydrophilic Bentonite nano-particles was developed. The results of morphological studies showed that all the membranes have asymmetric structure and the number of pores increased as well as mean pore radius was varied by the addition of hydrophilic Bentonite. The Energy-dispersive X-ray spectroscopy and Xray diffraction analysis of hydrophilic Bentonite embedded polyvinyl chloride membranes also supported the proper interaction between the polymer and inorganic nanoparticle. Change in contact angle data showed that the surface of membrane become more hydrophilic with increasing hydrophilic Bentonite content. Moreover, pure water flux of membranes was also calculated by using membrane in added end filtration setup. Flux was increased with increasing hydrophilic Bentonite content as a result of an increase in hydrophilicity. The resulting membranes also hada higher magnitude of tensile strength as well as elongation at break. However, agglomeration was observed for 1.5 and higher wt. \% of hydrophilic bentonite (HB) that adversely affected the membrane performance.

Keywords: Polyvinyl Chloride, Polyvinylpyrrolidone, Hydrophilic Bentonite, Antifouling Membrane, Improved Hydrophilicity
\end{abstract}

(c) RASĀYAN. All rights reserved

\section{INTRODUCTION}

In recent decades rapid population growth has influenced the rapid industrialization, depleted the natural resources, increased agriculture water demand, which in turn have polluted the environment and caused harsh climate situations. Water is an essential need of every living being on this planet, and a significant fraction of groundwater is used for industrial purpose and leaves the industry via polluted effluent stream. Such higher water demand is not only depleting the groundwater level but also increasing freshwater scarcity. Near about 1.2 billion population of the world is living under a shortage of safe drinkingwater ${ }^{1}$ and $50 \%$ population of the world will be living under water scarcity situation by $2030^{2}$.

This increasing demand has called out the strong need of research and development of favorable innovative technologies for the generation of clean water at a lower cost and lesser energy consumption with minimum incorporation of chemicals and least impact on the environment. Many water treatment technologies are in existence like adsorption, filtration, distillation, desalination, flocculation and sedimentation, sublimation, crystallization, membrane separation processes, and many more ${ }^{3}$.

Among various available technologies membrane separation processes are common in use for water purification, wastewater treatment, concentration in food, beverages, chemical, paper and pharmaceutical industries because of their advantages of continuous and low cost operation, easy to scale up, needless time and energy for the separation of undesired substances from raw water. Conventional separation processes such as distillation, crystallization or sublimation need a large amount of thermal energy for the desired separation while membrane separation processes do not require heating and use less energy for separation. This kind of separation process is entirely a physical process, and both outputs (permeate and

Rasayan J. Chem., 12(2), 707-718(2019)

http://dx.doi.org/10.31788/RJC.2019.1225158

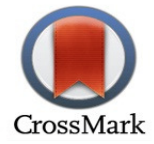


retentate) can be used for further applications. These processes involve a semi-permeable filter media "membrane" to separate particles from meso to nano range via different membrane separation processes like microfiltration, ultrafiltration, nanofiltration osmosis and dialysis working at different pressure range ${ }^{4}$.

The efficiency of membrane separation processes depends on the selected membrane material, preparation method and operating conditions. Usually, polymeric and ceramic materials made membranes are used for the application. Presently, a lot of commercially membranes are available, made of various polymers, such as cellulose acetate, polytetrafluoroethylene, polysulfone, polyacrylonitrile, polyethylene, polyvinyl chloride, polyethersulfone and polyvinylidene fluoride (PVDF) ${ }^{5-12}$.

Membrane Fouling is a major concern for a membrane manufacturer, which can critically reduce membrane performance. Fouling is the phenomenon in which particles, macromolecules, salts and so forth get deposited at the surface of the membrane or within the pores matrix.

It may diminish the membrane flux temporarily as well as permanently. Temporary fouling can be restored mechanically by applying back-pressures to wash the membrane to rejuvenate the initial flux. However, no technique can recover the permanent fouled membrane ${ }^{13}$.In general, membrane material with high hydrophilicity is preferred to decrease the temporary fouling. However, hydrophilic polymeric materials lack the desired mechanical properties which are also very much essential to sustain the membrane during the backwashing and air flushing to rejuvenate temporary fouled membrane. For this reason, a major concern is to prepare a membrane with high hydrophilicity with improved mechanical properties for its potential application in industrial and municipal requirements ${ }^{14,15}$.

Typically membrane fouling is mitigated by modifying the membrane surface. Surface modification techniques are of two types, twodimensions andthreedimensions. Two dimension techniques are a surface coating, surface bio-adhesion and surface grafting using surface modifiers either organic molecules or inorganic nanomaterials. Three dimension technique is a physical blending of modifiers to base polymer with surface segregation ${ }^{16}$. Amphiphilic polymers, which are compatible with a base polymer material for preparing membrane, are blended with membrane matrix during membrane preparation to improve antifouling properties in surface segregation method.

Various researchers have used the above technique to prepare porous polymeric mix matrix membranes using many different nanomaterials to investigate their effect on antifouling properties and performance of the membrane. Incorporation of these nanomaterials increases pore structure, higher hydrophilicity, surface morphology, strength which in turn results in better performance and antifouling nature of membrane ${ }^{17-23}$.

Many researchers have reported work on the fabrication of porous polymeric membranes using polyvinyl chloride (PVC). However, no such work has been published in the literature using polyvinylpyrrolidone (PVP) embedded Hydrophilic Bentonite nano clay for antifouling properties enhancement of membrane. Focus of the study is on the synthesis of high performing antifouling polymeric mix matrix membrane for the membrane separation processes for desired applications using polyvinyl chloride PVC as base polymer, PVP as Amphiphilic antifouling additive and hydrophilic Bentonite nano clay as dispersed inorganic phase using non solvent induced phase inversion process and to analyze improved surface, and mechanical properties relative to pure PVC membrane to understand the effect of grafting nanoparticles and to support its antifouling nature using scanning electron microscope (SEM),X-ray diffraction (XRD),Energy-dispersive X-ray spectroscopy EDX, Drop shape analyzer (DSA) and ultimate tensile machine (UTM).Surface morphology of modified membrane in terms of structure, size and distribution of pores, hydrophilicity, nanoparticle distribution, the mechanical stability of membrane as well as flow parameters for pure water flux were studied.

PVC is one of the widely used polymers worldwide for different applications because it is inexpensive, possess excellent chemical properties such as acid and alkali resistance,high mechanical strength good thermal properties ${ }^{24}$. Because of these properties, it is an excellent material for membrane preparation; however, it has a drawback of higher hydrophilicity which is not accepted in the membrane separation process for water purification.

Fang et al. have used phosphate based-zwitterionic polymer additive while Keeping PVC as base polymer while Demirel et al. have studied the $\mathrm{Fe}_{2} \mathrm{O}_{3}$ nano-composite to prepare PVC membrane and reported 
improved surface properties ${ }^{25,26}$. Similarly Ghazanfari et al., Rabiee et al. have respectively used alumina, zinc oxide inorganic particles to enhance the antifouling properties of PVC based membrane. ${ }^{27,28}$

Bentonite Clay minerals are hydrated phyllosilicates and may also be considered as hydroxides of silicon, aluminium, so far quite studies have been done on preparing polymer-based composites using clay fillers and few researchers have also used such composites to prepare membranes using different polymers. ${ }^{29-}$ ${ }^{33} \mathrm{PVP}$ is synthetic hydrophilic, water-soluble and biodegradable polymer and it deserves unique attention among the conjugated polymers due to its easy processibility, moderate electrical conductivity and rich in charge transport mechanism ${ }^{34}$.

\section{EXPERIMENTAL}

\section{Materials}

Polyvinyl chloride (PVC, MW=80000) and Hydrophilic Bentonite (HB) was supplied by Sigma-Aldrich. Polyvinyl Pyrrolidone (PVP) was bought from HPLC, Mumbai and used as pore former.N, NDimethylacetamide (DMAc), used as a polymer solvent was purchased by Spectrochem, Mumbai. All chemical and reagents were used as purchased without any further modification and treatment.

\section{Preparation of Mixed Matrix Membrane}

Non-solvent induced phase separation (NIPS) process was adopted for preparing Hydrophilic Bentonite (HB) grafted mixed matrix polyvinylchloride (PVC) membranes in lab ${ }^{35-37}$. A first known amount of HB was dispersed in DMAc and sonicated for 2 hours to have a homogenous suspension for a polymeric solution. Then pore former PVP was mixed to the solution and the solution was stirred at room temperature for 2 hours. Subsequently, PVC was added to the solution and mixed by constant stirring for a day until the solution gets homogenous completely. After this solution was further sonicated to remove trapped air bubble in solution and cast with casting knife on a glass plate. After casting the glass plate was immediately immersed in a deionized water bath, which works as Non-solvent and phase inversion takes place and membranes were formed which were easily detached from the plate. The membrane was immersed in distilled water for 48 hours for complete exchange of solvent DMAc. Membranes are dried and stored for further use. In this experiment,5 different samples of various HB composition and constant polymeric concentration in all casting solution were $20 \%$. Thecomposition of all membrane samples was given in Table-1.

Table-1: Composition of Dope Solution for Membrane Preparation

\begin{tabular}{c|c|c|c|c}
\hline Membrane & PVC (wt \%) & PVP (wt \%) & HB (wt \%) & DMAc(wt \%) \\
\hline M1 & 19 & 1 & 0 & 80 \\
\hline M2 & 19 & 1 & 0.5 & 79.5 \\
\hline M3 & 19 & 1 & 1.0 & 79.0 \\
\hline M4 & 19 & 1 & 1.5 & 78.5 \\
\hline M5 & 19 & 1 & 2.0 & 78.0 \\
\hline
\end{tabular}

\section{Characterization of Membranes SEM Analysis}

The scanning electron microscope was used to visualize the morphology of the membrane surface. All the analysis is done using instrument EVO - Scanning Electron Microscope MA15 /18, CARL ZEISS MICROSCOPY LTD. Since the sample is non-metallic, it is coated with gold before observation. Digimizer image analysis software was further used to analyze these SEM images for pore size distribution and to calculate the mean pore size.

\section{EDX Analysis}

Energy-dispersive X-ray spectroscopy (EDS) was used to verify the presence as well as the dispersion of HB within the membrane. For this purpose 51N1000 - EDS System, CARL ZEISS MICROSCOPY LTD is used.

\section{XRD Analysis}

$\mathrm{X}$-ray diffraction was done to verify the interaction between polymer and HB atoms. Samples were scanned at $2 \Theta$ angle from 5-70 .X-ray diffractometer Rigaku Miniflex 600 Desktop X-Ray Diffraction 
System, RIGAKU Corporation used for analysis was equipped with monochromatic $\mathrm{Cu}-\mathrm{K} \alpha$ radiation $(\lambda=0.154 \mathrm{~nm})$

Table -2: Element Weight Percentage of the Membrane Obtained by EDS

\begin{tabular}{c|c|c|c|c|c}
\hline $\begin{array}{c}\text { Element } \\
(\mathrm{Wt} \%)\end{array}$ & M1 & M2 & M3 & M4 & M5 \\
\hline $\mathrm{C}$ & 35.4 & 32.30 & 56.76 & 28.30 & 54.75 \\
\hline $\mathrm{O}$ & 9.80 & 24.10 & 9.08 & 18.10 & 6.87 \\
\hline $\mathrm{Al}$ & - & 0.65 & 0.52 & 0.35 & 21.05 \\
\hline $\mathrm{Si}$ & - & 0.98 & 0.40 & 1.40 & $9 . .39$ \\
\hline $\mathrm{Cl}$ & 54.80 & 41.87 & 33.24 & 51.85 & 7.94 \\
\hline
\end{tabular}

Table-3: Major Peaks Obtained in XRD Patterns of Pure PVC Membrane, Pristine HB Particles and HB Doped

\begin{tabular}{c|c} 
& Membranes \\
\hline Membrane & MAJOR PEAKS (2 THETA) \\
\hline M1 & $18.86,24.37,40.05$ \\
\hline M2 & $18.34,23.2,40.08$ \\
\hline M3 & $19.24,24.66,39.84$ \\
\hline M4 & $18.95,24.26,39.81$ \\
\hline M5 & $20.19,25.17,35.58,39.97,62.06$ \\
\hline Pristine HB & $6.88,19.81,28.64,34.68,53.99,61.84$ \\
\hline
\end{tabular}

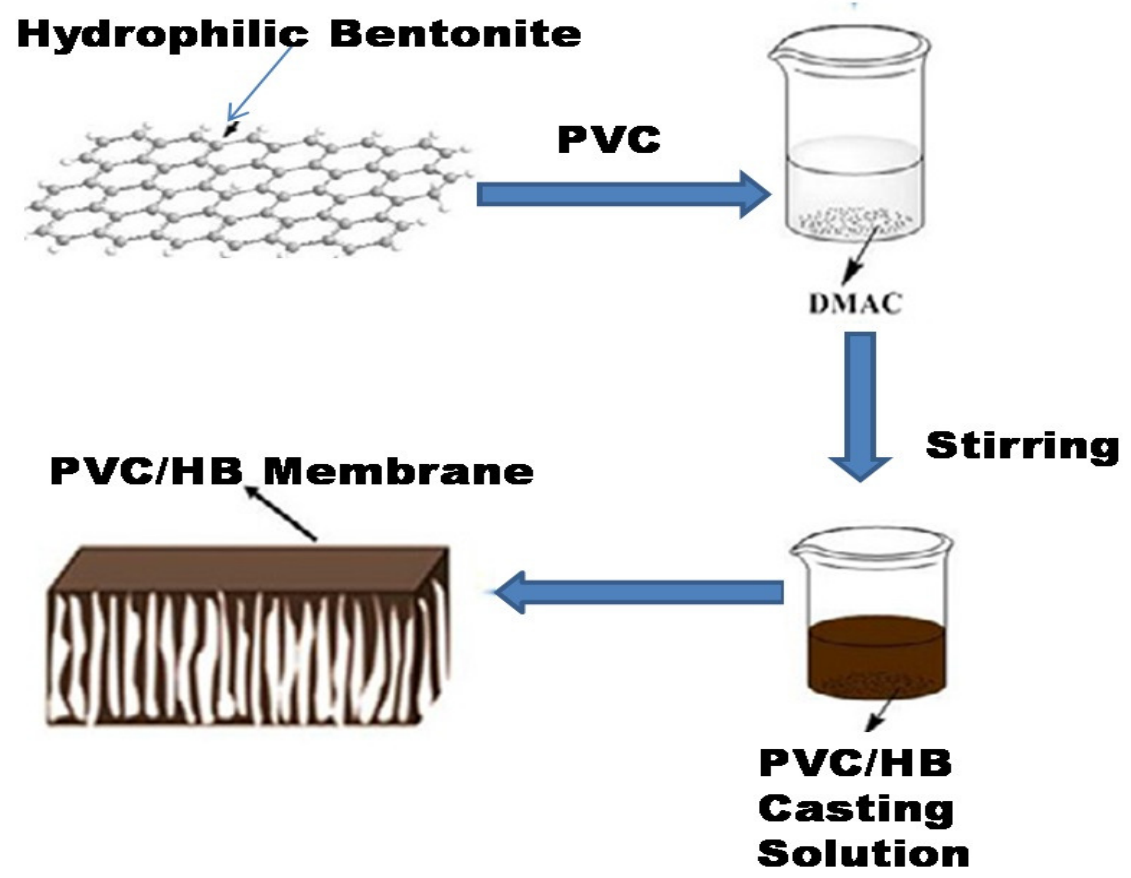

Fig.-1: Schematic Diagram of the Preparation of PVC/HB Membrane

\section{Mean Pore Size and Pore Count and Porosity}

SEM images were analyzed by Digimizer image analysis software and mean pore size was calculated by this.

To measure the porosity of membrane a piece of known dimensions was weighed in a dry state and then it was immersed in distilled water for 24 hours .Then water on the surfacewas soaked by filter paper, and it was weighted again.

Porosity is calculated as:

$$
\phi(\%)=\frac{W w-W D}{\rho W * V} * 100 \%
$$


Where $\mathrm{Ww}_{\mathrm{w}}$ and $\mathrm{W}_{\mathrm{D}}$ were the weight of the sample in the wet and dry state. $\mathrm{V}$ was the volume of membrane and $\rho_{\mathrm{w}}$ was the density of water ${ }^{36}$.

\section{Contact Angle Test}

Drop shape analyzer DSA25, KRUSSGmbH, Germany was used to know the contact angle of the samples which eventually show the hydrophilicity of the membrane. Average of 4 scans were reported to diminish the scanning errors.

\section{Mechanical Properties}

Mechanical properties of the membrane, i.e., tensile strength and elongation at break were calculated by tensile testing machine INSTRON 5982 Floor Model System, USA. All the membranes were of size 4 x 1 $\mathrm{cm} \mathrm{x} \mathrm{cm}$, and samples were analyzed at a rate of $1 \mathrm{~mm} / \mathrm{min}$ using $500 \mathrm{~N}$ load cells. All the tests were conducted at four times, and the average results were reported.

\section{Pure Water Flux}

A self-made dead end lab scale filtration setup was fabricated to measure the pure water flux of membranes. The pre-wetted membraneswere compacted for $30 \mathrm{~min}$ at a transmembrane pressure of 2 bar. To decrease the compaction effect and then the pressure was reduced to 1.5bar. At steady state, water flux was calculated using the following equation ${ }^{36}$ :

$$
J_{0}=\frac{V}{A t}
$$

Where $J_{0}$ was pure water flux (PWF), $V$ was the volume of collected water, $A$ was membrane area, and $t$ was the time.

\section{SEM}

\section{RESULTS AND DISCUSSION}

SEM was used to study the change in surface morphology of neat PVC membrane with hydrophilic Bentonite. The SEM images showed the expected asymmetric structure on the surface of the membrane. Pores were observable in the entire membrane surface. It was seen in the SEM images of (Fig.-2) that M1 was denser structure and effect of the addition of $\mathrm{HB}$ was easily seen in the images. Addition of dopant had made the surface rougher than the pure PVC membrane. It was observed that by adding filler, clusters were formed within the membrane surface. With increasing, filler amount surface becomes more irregular and looks stronger with multilayer formation because of fillers. However, in M5 surface looks totally distorted with large numbers of layers in surface and huge Cluster appears on the surface which supports XRD data of sample too.

Furthermore, this could also be seen by Fig.-2 that all the polymeric membranes synthesized had the macro-void structure, which can be because of the instantaneous de-mixing may have occurred during phase inversion process because of total miscibility between DMAC and non-solvent,i.e. water. When the different amount of dopant was added in the preparation, the difference in macro voids was also seen on the surface of the membrane. These may be because of the fact that hydrophilic Bentonite gives faster affinity to water during the phase inversion process.

When the casted membrane was immersed into the non-solvent during the phase inversion, the hydrophilic additives, as well as water-soluble PVP, tends to leach out into the non-solvent and retains the non-polar PVC on the non-woven sheet. Therefore asymmetric pores were formed. Because of polymerpolymer interaction between PVC and PVP, some part of PVP will remain in the polymer matrix even after keeping the sheet in non-solvent for a long time. When HB particles were doped in the mixture, there must be some interaction between HB and PVP. Since HB was hydrophilic, it would also try to move out during phase inversion through the surface and pores of the membranes. Since PVP was amphiphilic, it would bind the PVC matrix as well as holds the HB within the polymeric phase. Thus, the process results in increased porosity and enhancement in permeate flux as observed in cross-sectional SEM images, i.e., Fig.-2 and from Fig.-7.

However, as the amount of HB is increased, it will stay more in the polymer matrix and will be placed in the pores within the structure. It furthermore would result in the more significant amount of particles 
RASĀYAN J. Chem.

Vol. 12 | No. 2 |707 - 718| April - June | 2019

leaching out in the process and creating macro voids as shown in SEM images of M4 and M5 in Fig.-2. This also affects the porosity of the membrane as a large amount of dopant, which is agglomerating in the membrane, will increase the viscosity of the casting solution and in turn lead to pore blockage within PVC structure which in turn decreases the porosity as well as permeate flux of the membrane which was shown in Fig.-4b and Fig.-7.

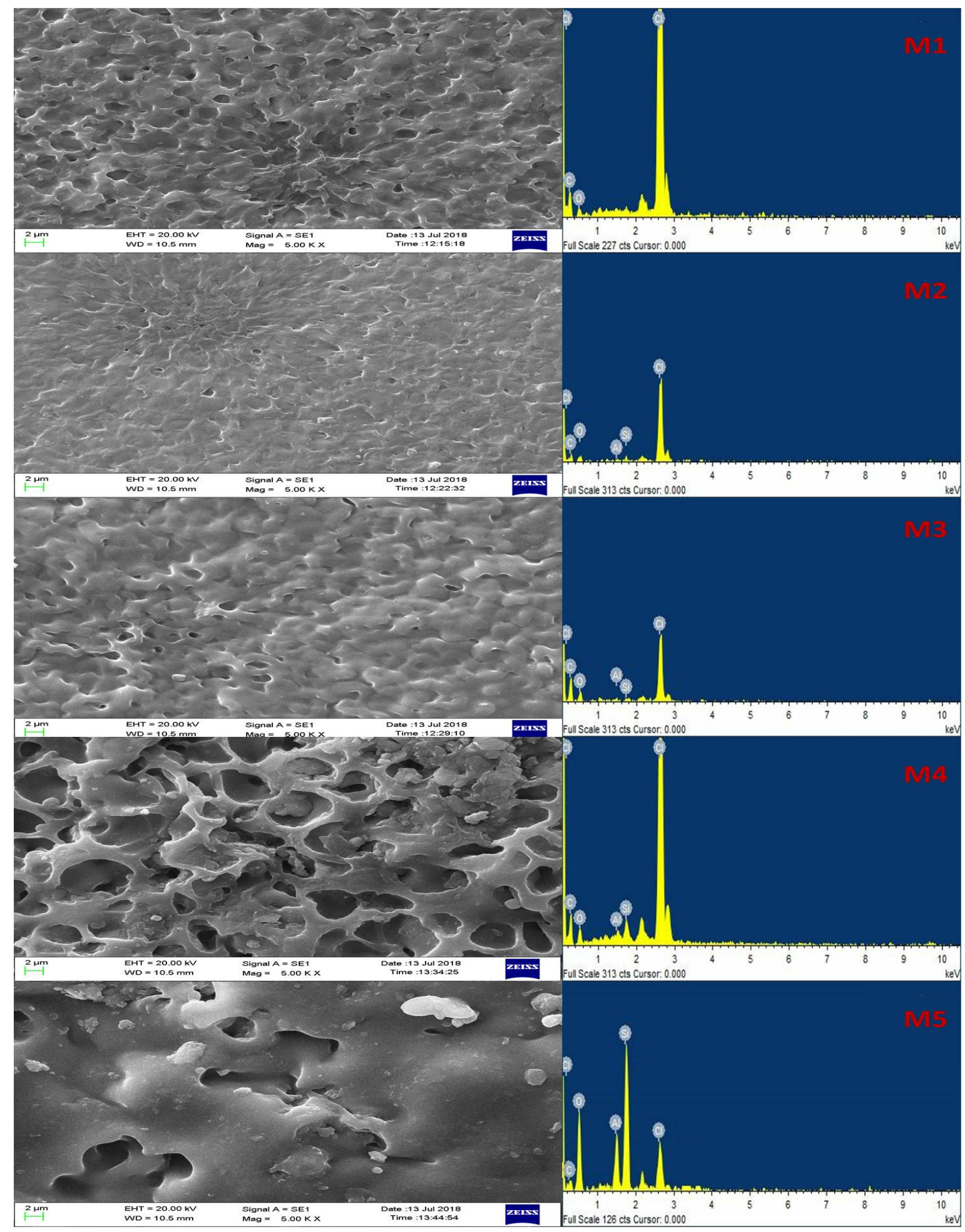

Fig.-2: Surface Morphology and Energy-Dispersive X-Ray Spectroscopy (EDS) Data of the Top Surface of Membranes 


\section{EDX}

Energy-dispersive X-ray spectroscopy (EDX) data as shown in Fig.-2 and Table-2 verified the presence as well as the dispersion of $\mathrm{HB}$ within the membrane.

EDX data of $\mathrm{M} 1$ shows the presence of $\mathrm{C}, \mathrm{O}$, and $\mathrm{Cl}$ in pristine membrane and addition of $\mathrm{HB}$ was easily detected in the plots of M2-M5 in the Fig.-2 with higher intensity of Si, Al with an increased amount of HB.
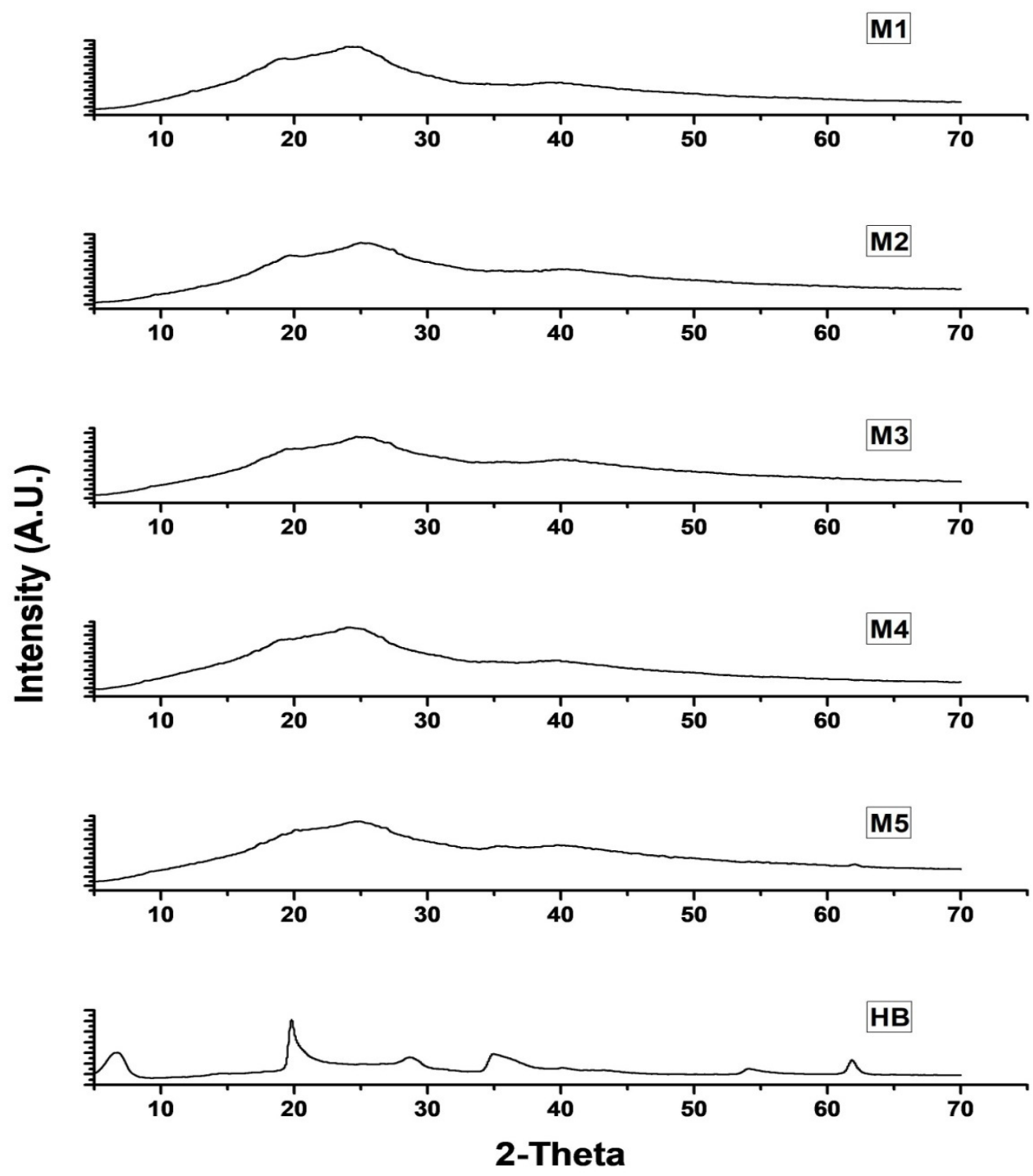

Fig.-3: XRD Patterns of Pure PVC Membrane, Pristine HB Particles and HB Doped Membranes

\section{XRD}

The presence of HB particles can also be verified by XRD analysis. XRD patterns of pure PVC membrane, pristine HB particles, and HB doped membranes are shown in Fig.-3 and Table-3. All peaks were broad peaks which indicated about the amorphous nature of the material which was expected too for polymeric membrane while pristine HB particles give strong diffraction crystalline peaks which were a common structure for inorganic particles ${ }^{32}$. The diffraction patterns of $0.5 \% \mathrm{HB}$ grafted membrane show a slight shifting of peaks towards the low Theta angle confirming the presence of inorganic material. Same results were obtained for $1.0 \%, 1.5 \%$ HB grafted membrane i.e.M3, M4 respectively. However, for 
the M5 two more peaks were also observed in the diffraction patterns which were because of the high amount of HB particles present in M5 membrane.

\section{Pore Size Distribution and Porosity}

An image analyzer software was used to understand briefly the change in the surface of the membrane by the addition of nanoparticles.SEM images of the top surface of each membrane were analyzed. It was observed in results that the number of pores is changing as well as the mean pore radius of pores as HB content was increased. However such pattern did not show in case of M5. In the Fig-4a, it was seen that the data from image analyzer show that the pore count was 143, 225, 379, 346 and 284 for M1, M2, M3, M4,and M5 PVC membranes, respectively. It was clearly seen that addition of hydrophilic Bentonite had increased the number of pores initially but as the concentration of HB increased in polymeric solution and agglomeration of particles took place which in turn makes the solution more viscous and resulted in the blockage of pores. That is the reason that the number of pores is decreasing in M4 and M5. It also affects the porosity of the membrane obtained by a swelling test of the membrane. Variation in porosity is shown by Fig-4b.The pore size distribution of membranes is shown in Fig.-4c. It was observed that most of the fraction of pores was in size range of below $1 \mu \mathrm{m}$ which show the membrane samples were suitable for filtration processes. However, a very low fraction of pores was found in size range between 3-3.5 $\mu \mathrm{m}$ $\max$.

\section{Contact Angle}

The contact angle is the critical characteristic of the membrane which expresses the hydrophilic or hydrophobic nature of the membrane. Lower contact angle values show the strong hydrophilicity of the material. Changes in contact angle of all samples are shown in Fig-5. Pure PVC membrane M1 shows the highest contact angle at $68.9^{\circ}$ and as the hydrophilic bentonite was added to the polymeric solution the composite membrane showed a lower contact angle. As the HB amount was increased from 0 to $2 \%$, the contact angle was decreased from $68.9^{\circ}$ to $47.1^{\circ}$ which shows the hydrophilicity of the membrane surface was enhanced with the addition of hydrophilic Bentonite. Such an increase in hydrophilicity of membrane surfaces by adding inorganic material was also reported in various reported literature. ${ }^{9}$

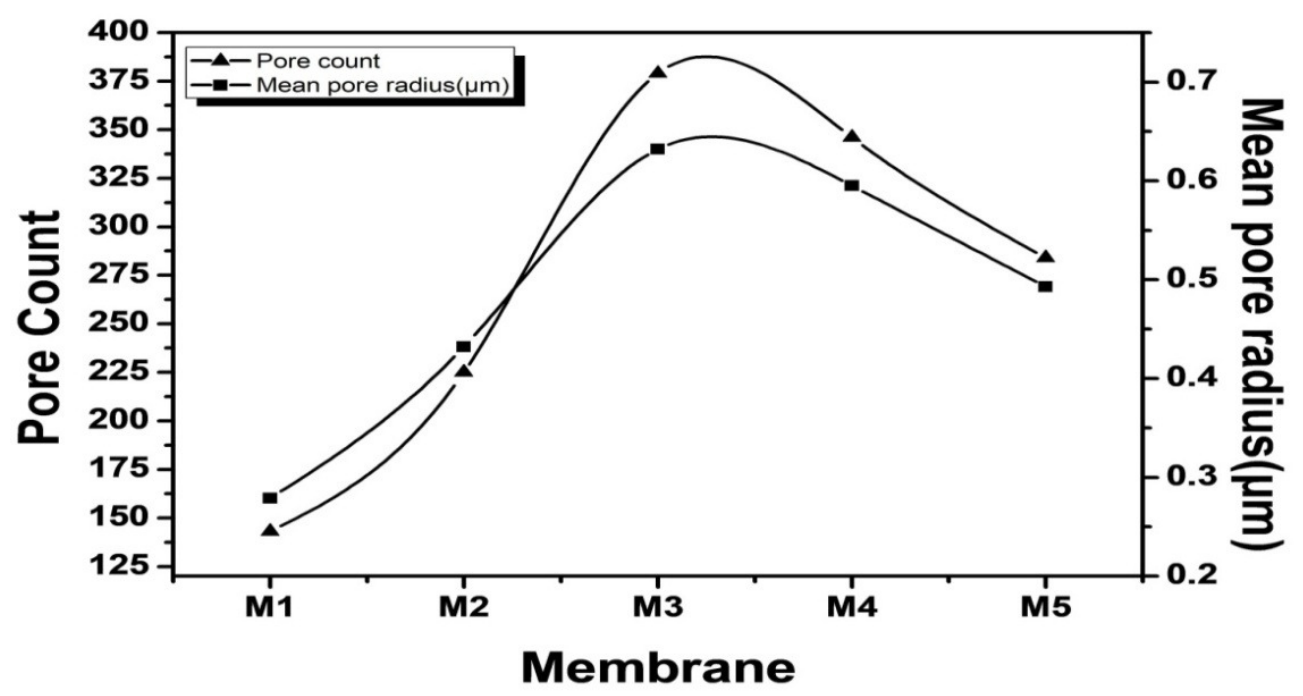

\section{Mechanical Properties}

Fig.-4a: Mean Pore Radius and Pore Count of Membranes

Mechanical properties are essential characteristics of a membrane as they show the long-term stability for the performance of membrane at high pressures.As shown in Fig-6 ,Incorporation of inorganic materials improved the tensile strength of the material but as the agglomeration of particles took place with higher amount of HB and with the increase of viscosity of polymer blocking of pores took place which in turn reduced the flexibility of the material by decreasing the porosity and make the material more brittle and decreased the tensile strength as well as elongation at break. 


\section{Pure Water Flux}

Pure water flux of a membrane depends on various factors like hydrophilicity, thickness, pore radius as well as porosity. Grafting of hydrophilic Bentonite not just improves the hydrophilicity of membrane but also has improved other factors which play a great role for enhancement of pure water flux. Bentonite improved the wetting rate of the membrane which in turn increased the water permeation through the membrane. Pure water flux was obtained for all samples as shown in Fig-7, by performing filtration experiments on a dead end filtration cell at lab scale by cutting $5 \mathrm{~cm}$ diameter circular membrane and operating pressure of $2 \mathrm{~atm}$.

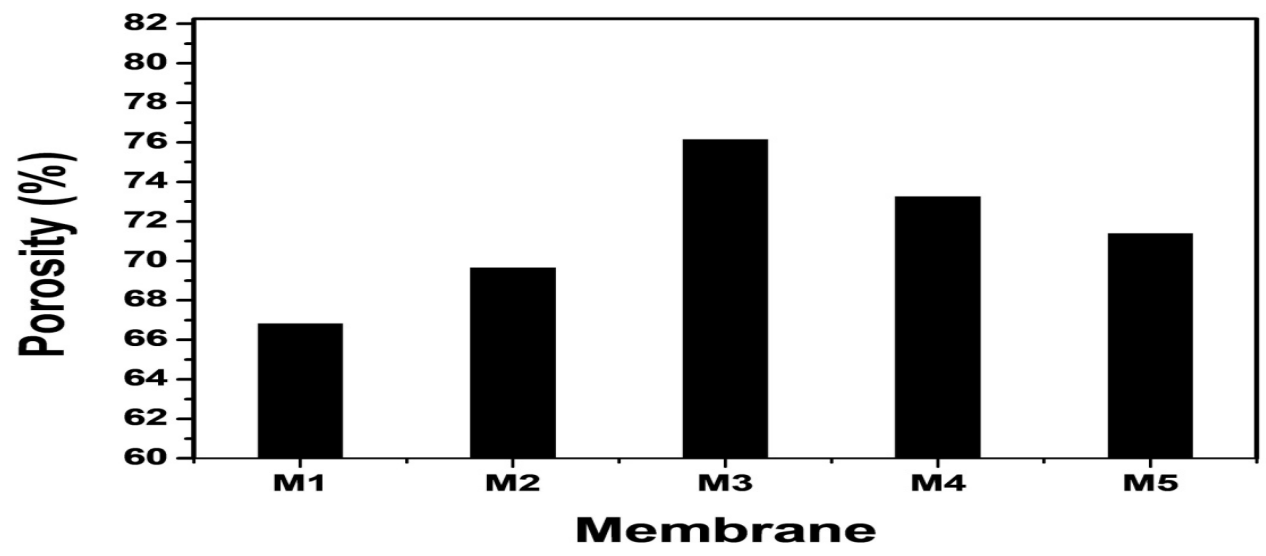

Fig.-4b: Variation in Porosity with Different Concentration of HB

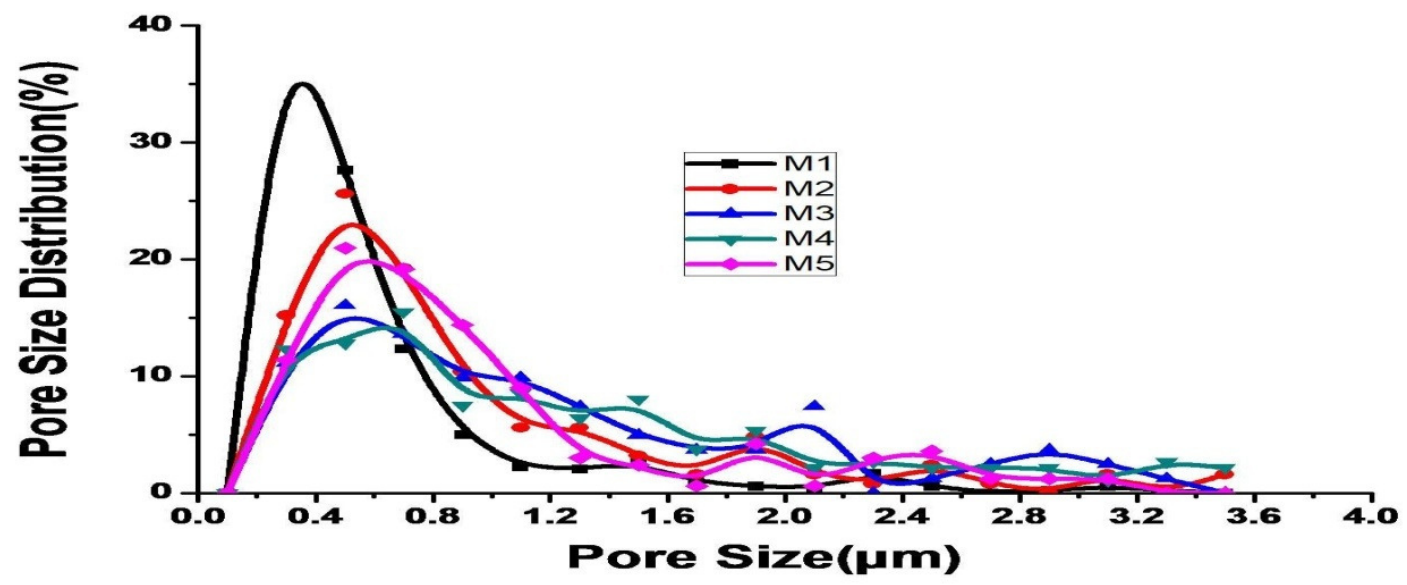

Fig.-4c: Pore Size Distribution of PVC/HB Membrane

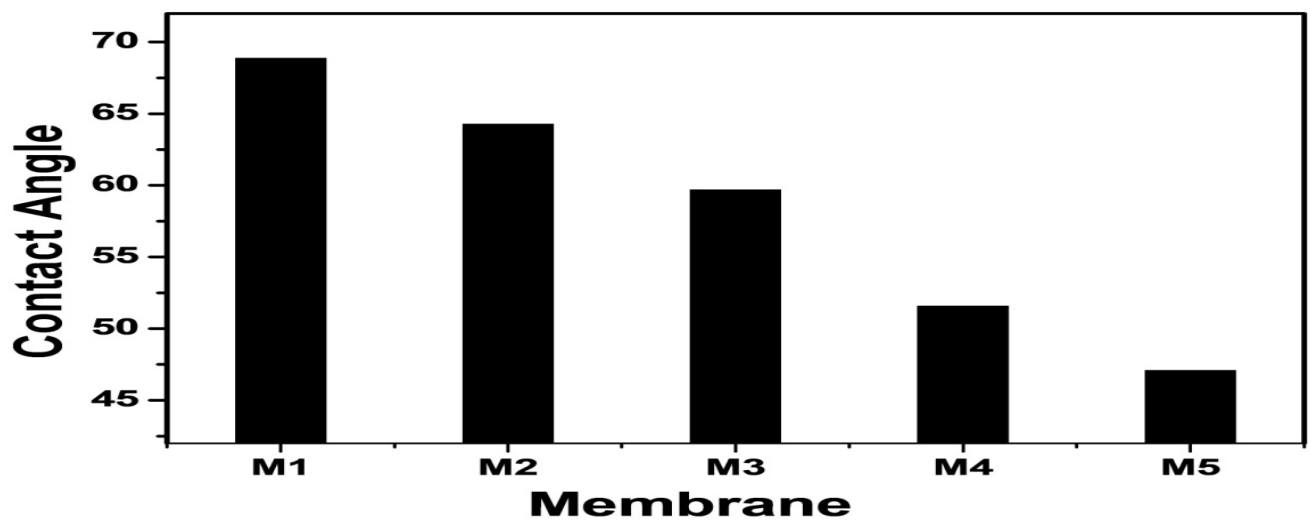

Fig.-5: Water Contact Angle Measurement Results of Membranes 


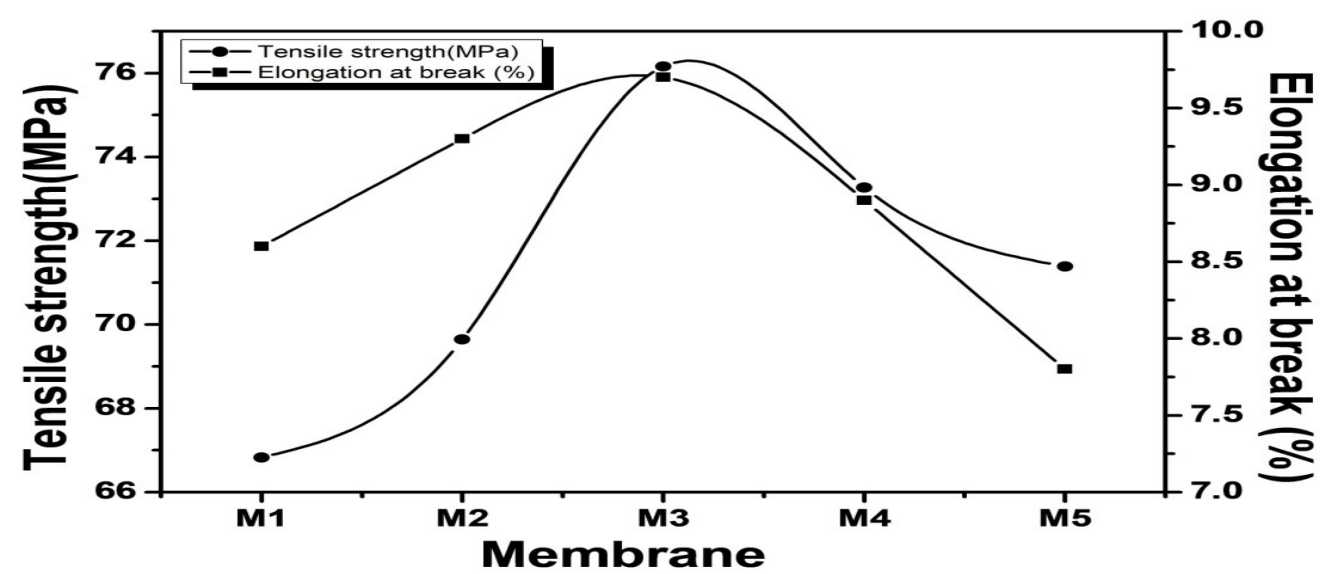

Fig.-6: Variation in Tensile Strength and Elongation at Break of Membranes

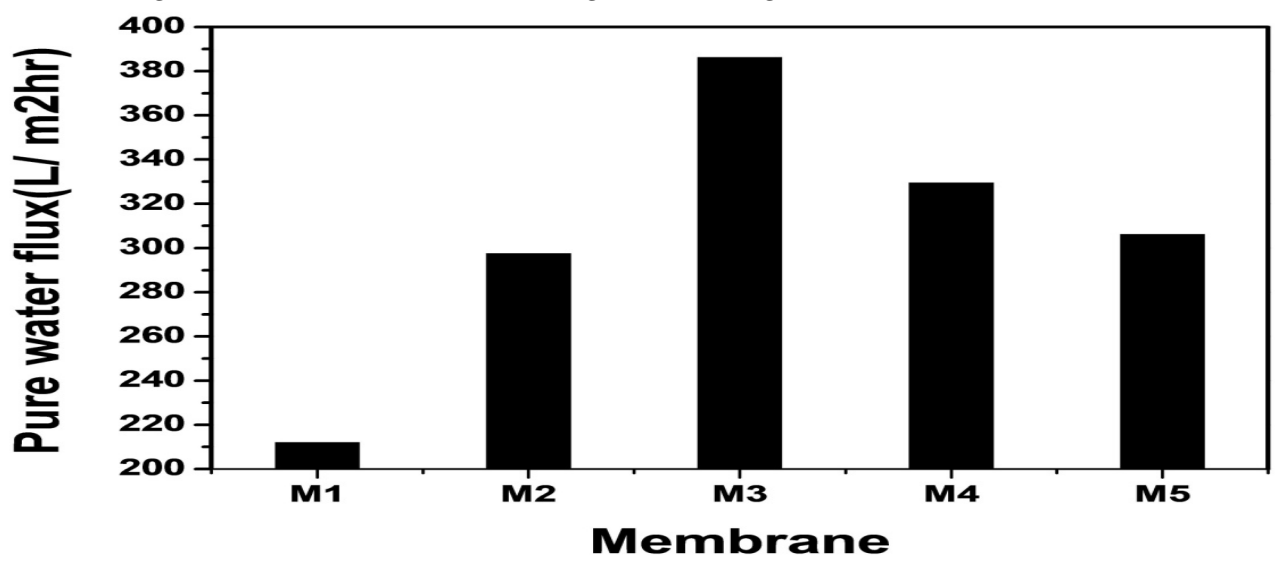

Fig.-7: Comparison of Pure Water Flux of Membranes

CONCLUSION

Composite membranes of PVC with different amount of HB particles were synthesized in lab and characterization was done for analysis. PVC is a widely used polymer in various fields because of its versatile properties. The presence of chlorine site present in long aliphatic chains of PVC makes it appropriate for chemical modification as chlorine is an easily leaving group. After modification, PVC lost its strength which was regained by modifying with inorganic HB particles. The compatibility and interaction between PVC and HB were confirmed by SEM, EDS and XRD analysis. The results showed that addition of HB particles had improved the number of pore counts as well as mean pore size till the optimum concentration of $\mathrm{HB}$ particles, i.e., $1 \%$. This membrane had shown superior hydrophilicity, porosity, and pure water flux as compared to pristine PVC membrane M1. The blended membranehad shown higher tensile strength as well as elongation at break. Such properties of blend membrane defiantly improved antifouling behavior of the polymericmembrane.

The blending of PVC with HB particles improved its antifouling nature as well as improved the performance of the membraneand optimum blending concentration of HB particle was found to be $1 \%$. The prepared membranes had an average pore size range below $1 \mu \mathrm{m}$ which was quite suitable for many industrial and municipal separation applications. Various researchers have also used membranes with such pore size range for the separation of salts, humic acid, BSA, and oil from aqueous solutions by using a membrane with this pore size range ${ }^{37-41}$.

\section{REFERENCES}

1. M. A. Shannon, P. W. Bohn, M. Elimelech, J. G. Georgiadis, B. J. Mariñas and A. M. Mayes, Nature, 452, 301(2008), DOI:301. 10.1038/nature06599

2. F. A. G., W. Rong and H. M. X.,Angewandte Chemie International Edition, 54, 3368(2015), DOI:10.1002/anie.201409783 
RASĀYAN J. Chem.

Vol. 12 | No. 2 |707 - 718| April - June | 2019

3. D. M. Warsinger, S. Chakraborty, E. W. Tow, M. H. Plumlee, C. Bellona, S. Loutatidou, L. Karimi, A. M. Mikelonis, A. Achilli, A. Ghassemi, L. P. Padhye, S. A. Snyder, S. Curcio, C. D. Vecitis, H. A. Arafat and J. H. Lienhard, Progress in Polymer Science, 81, 209(2018), DOI:10.1016/j.progpolymsci.2018.01.004

4. S.-L. Wee, C.-T. Tye and S. Bhatia,Separation and Purification Technology, 63, 500(2008), DOI:10.1016/j.seppur.2008.07.010

5. G. Mendes, M. Faria, A. Carvalho, M. C. Gonçalves and M. N. de Pinho, Carbohydrate Polymers, 189, 342(2018), DOI:10.1016/j.carbpol.2018.02.030

6. W. Qin, Z. Xie, D. Ng, Y. Ye, X. Ji, S. Gray and J. Zhang, Water Research, 130, 343(2018), DOI:10.1016/j.watres.2017.12.002

7. T. Hwang, J.-S. Oh, W. Yim, J.-D. Nam, C. Bae, H.-i. Kim and K. J. Kim, Separation and Purification Technology, 166, 41(2016), DOI:10.1016/j.seppur.2016.04.018

8. Y. Peng, F. Guo, Q. Wen, F. Yang and Z. Guo, Separation and Purification Technology, 184, 72 (2017), DOI:10.1016/j.seppur.2017.04.036

9. A. Akbari, R. Yegani, B. Pourabbas and A. Behboudi, Chemical Engineering Research and Design, 109, 282(2016), DOI:10.1016/j.cherd.2016.01.031

10. L. Marbelia, M. R. Bilad, N. Bertels, C. Laine and I. F. J. Vankelecom, Journal of Membrane Science, 498, 315(2016), DOI:10.1016/j.memsci.2015.10.017

11. B. Khorshidi, J. Hajinasiri, G. Ma, S. Bhattacharjee and M. Sadrzadeh, Journal of Membrane Science, 500, 151(2016), DOI:10.1016/j.memsci.2015.11.015

12. C. Y. Lai, A. Groth, S. Gray and M. Duke, Water Research, 57, 56(2014), DOI:10.1016/j.watres.2014.03.005

13. D. Rana and T. Matsuura, Chemical Reviews, 110, 2448(2010), DOI: 10.1021/cr800208y

14. P. Le-Clech, V. Chen and T. A. G. Fane, Journal of Membrane Science, 284, 17(2006), DOI:10.1016/j.memsci.2006.08.019

15. A. G. Fane and C. J. D. Fell, Desalination, 62, 117(1987), DOI:10.1016/0011-9164(87)87013-3

16. R. Zhang, Y. Liu, M. He, Y. Su, X. Zhao, M. Elimelech and Z. Jiang, Chemical Society Reviews, 45, 5888-5924,(2016), DOI: 10.1039/C5CS00579E

17. T. A. Saleh and V. K. Gupta, Separation and Purification Technology, 89, 245(2012), DOI:10.1016/j.seppur.2012.01.039

18. Y. Jafarzadeh, R. Yegani and M. Sedaghat, Chemical Engineering Research and Design, 94, 417(2015), DOI:10.1016/j.cherd.2014.08.017

19. E. Shokri, R. Yegani, B. Pourabbas and N. Kazemian, Applied Clay Science, 132-133, 611(2016), DOI:10.1016/j.clay.2016.08.011

20. N. Maximous, G. Nakhla, W. Wan and K. Wong, Journal of Membrane Science, 341, 67(2009), DOI:10.1016/j.memsci.2009.05.040

21. T. Wu, B. Zhou, T. Zhu, J. Shi, Z. Xu, C. Hu and J. Wang, RSC Advances, 5, 7880(2015), DOI: 10.1039/C4RA13476A

22. Y. Zhang, X. Shan, Z. Jin and Y. Wang, Journal of Hazardous Materials, 192, 559(2011), DOI:10.1016/j.jhazmat.2011.05.058

23. J. Huang, G. Arthanareeswaran and K. Zhang, Desalination, 285, 100(2012), DOI: 10.1016/j.desal.2011.09.040

24. X. Zhang, Y. Chen, A. H. Konsowa, X. Zhu and J. C. Crittenden, Separation and Purification Technology, 70, 71(2009), DOI:10.1016/j.seppur.2009.08.019

25. L.-F. Fang, S. Jeon, Y. Kakihana, J.-i. Kakehi, B.-K. Zhu, H. Matsuyama and S. Zhao, Journal of Membrane Science, 528, 326(2017), DOI:10.1016/j.memsci.2017.01.044

26. E. Demirel, B. Zhang, M. Papakyriakou, S. Xia and Y. Chen, Journal of Membrane Science, 529, 170(2017), DOI: 10.1016/j.memsci.2017.01.051

27. D. Ghazanfari, D. Bastani and S. A. Mousavi, Journal of Water Process Engineering, 16, 98(2017), DOI:10.1016/j.jwpe.2016.12.001

28. H. Rabiee, V. Vatanpour, M. H. D. A. Farahani and H. Zarrabi, Separation and Purification Technology, 156, 299(2015), DOI:10.1016/j.seppur.2015.10.015 
RASĀYAN J. Chem.

Vol. 12 | No. 2 |707 - 718| April - June | 2019

29. F. Bergaya and G. Lagaly,F. Bergaya and G. Lagaly, Developments in Clay Science, 5, 1(2013), DOI: $10.1016 / \mathrm{B} 978-0-08-098258-8.00001-8$

30. S. Pavlidou and C. D. Papaspyrides, Polymer Science, 33, 1119(2008), DOI:10.1016/j.progpolymsci.2008.07.008

31. N. Ghaemi, S. S. Madaeni, A. Alizadeh, H. Rajabi and P. Daraei, Journal of Membrane Science, 382,135(2011), DOI:10.1016/j.memsci.2011.08.004

32. P. Anadão, L. F. Sato, H. Wiebeck and F. R. Valenzuela-Díaz, Applied Clay Science, 48, 127(2010), DOI: 10.1016/j.clay.2009.12.011

33. S. Taghaddosi, A. Akbari and R. Yegani, Chemical Engineering Research and Design, 125, 35(2017), DOI:10.1016/j.cherd.2017.06.036

34. S.S Basha, G.S.Sundari, K. Kumar and M. Rao, Rasayan J. Chem., 9, 348(2016),

35. N. Pezeshk and R. M. Narbaitz, Desalination, 287, 247(2012), DOI:10.1016/j.desal.2011.11.048

36. S. Vanitha, P. Vijayalakshmi , P.K. Raji and M. Praba, Rasayan J. Chem., 12(1), 32(2019), DOI: 10.31788/RJC.2019.1213093

37. A. K. Tiwari and S.Nath, Rasayan J. Chem., 12(1),73(2019), DOI: 10.31788/RJC.2019.1213093

38. B. Saini, S. Khuntia and M. K. Sinha, Journal of Membrane Science, 572, 184(2019), DOI:10.1016/j.memsci.2018.11.017

39. M. Safarpour, A. Khataee and V. Vatanpour, Journal of Membrane Science, 489, 43(2015), DOI:10.1016/j.memsci.2015.04.010

40. S.-Y. Wang, L.-F. Fang, L. Cheng, S. Jeon, N. Kato and H. Matsuyama, Journal of Membrane Science, 549, 101(2018), DOI:10.1016/j.memsci.2017.11.074

41. A. Behboudi, Y. Jafarzadeh and R. Yegani, Chemical Engineering Research and Design, 114, 96(2016), DOI:10.1016/j.cherd.2016.07.027

42. T. D. Kusworo, N. Aryanti, Qudratun and D. P. Utomo, Chemical Engineering Journal, 347, 462(2018), DOI:10.1016/j.cej.2018.04.136

43. E. Yuliwati and A. F. Ismail, Desalination, 273, 226(2011), DOI:10.1016/j.desal.2010.11.023

[RJC-5158/2018] 